\title{
Sputnik and Mavirus: not more than satellite viruses
}

\author{
Mart Krupovic and Virginija Cvirkaite-Krupovic
}

In response to our Comment (Virophages or satellite viruses? Nature Rev. Microbiol. 9, $762-763(2011))^{1}$ regarding the place of the so-called virophages in the viral world, Matthias Fischer puts forth two arguments that, in his opinion, distinguish virophages from classical satellite viruses (Sputnik and Mavirus: more than just satellite viruses. Nature Rev. Microbiol. 5 Dec 2011 (doi:10.1038/ nrmicro2676-c1) $)^{2}$.

In his first argument, Fischer cites the definition of satellite viruses provided by the International Committee on Taxonomy of Viruses (ICTV) - "Satellites are sub-viral agents which lack genes that could encode functions needed for replication" (REF. 3) and argues that Sputnik and Mavirus cannot be considered satellite viruses because they are not small and they encode their own DNA replication enzymes. In fact, the ICTV definition rather accurately describes the main features of Sputnik and Mavirus. The term subviral agents, however, should not necessarily be understood as 'smaller than viruses' per se, but should rather be interpreted as 'lacking certain functions or features'. Besides, not all satellite viruses are smaller than 'autonomous' viruses; for example, both the genome and virion sizes of adeno-associated virus (AAV), which relies on co-infection with adenovirus for reproduction, are larger than those of the circoviruses. Also, 'virus replication' has been confused with 'genome replication', as these terms are not synonymous. Virus replication refers to the entire process of virus multiplication, from the onset of infection to the assembly and release of viral progeny. In any case, AAV encodes its own enzyme for replication of the singlestranded DNA genome by a rolling-hairpin mechanism $^{4,5}$.

The second argument from Fischer is that Sputnik and Mavirus are "the first viruses to truly infect another virus inside a common host cell” (REF. 2.) He presents a transmission electron micrograph to illustrate this point: in the case of a co-infection of a Cafeteria roenbergensis cell with Mavirus and its helper, Cafeteria roenbergensis virus, only Mavirus particles are visible. However, the same negative effect on the production of the helper virus has been reported for classical satellite viruses (see the section entitled 'Effect of the satellite virus on the helper virus' in our Comment) ${ }^{1}$.

Based on the presence of common promoter and polyadenylation signals ${ }^{6}$, Fischer claims that transcription is the only function supplied by their helpers to Sputnik and Mavirus (this remains to be confirmed experimentally) and, hence, that they are bona fide 'autonomous' viruses that infect the helper viruses and not host cells. However, Mavirus and Sputnik do not 'truly infect' their helper viruses any more than classical satellite viruses do. For example, satellite tobacco necrosis virus (STNV) does not rely on the host cell for genome replication and transcription (its single-stranded RNA genome serves as mRNA); rather, it hijacks the appropriate machinery, an RNA-dependent RNA polymerase, from its helper virus, TNV. STNV virion assembly occurs in the cytoplasm in close proximity to the TNV genome replication and virion assembly centres; this causes production of the helper virus to reduce to non-detectable amounts (when an excess of STNV is used during co-infection). More conceptually, considering that upon viral infection a cell is transformed into a viral organism, a virocell (sensu Forterre) ${ }^{7}$, any satellite virus (not just Sputnik and Mavirus) infects a viral organism, as the cellular organism simply ceases to exist. Irrespective of what type of genome a virus has, how big a virus it is or which function (or functions) it lacks, as long as it cannot reproduce in a host cell without the aid of another virus, it is a satellite virus, a term which was coined back in 1962 (REF. 8) to describe such a relationship.

To conclude, Sputnik and Mavirus are not more than satellite viruses - and there is no depreciation or disgrace in that. Their proper classification as satellite viruses will help to more fully comprehend the diversity and evolution within this fascinating but underappreciated class of viruses.

Mart Krupovic and Virginija Cvirkaite-Krupovic are at the Institut Pasteur, Department of Microbiology, 25 rue du Dr. Roux, 75015 Paris, France.

Correspondence to M.K. e-mail:krupovic@pasteur.fr

Published online 5 December 2011

1. Krupovic, M. $\&$ Cvirkaite-Krupovic, V. Virophages or satellite viruses? Nature Rev. Microbiol. 9, 762-763 (2011).

2. Fischer, M. G. Sputnik and Mavirus: more than just satellite viruses. Nature Rev. Microbiol. 5 Dec 2011 (doi: 10.1038/nrmicro2676-c1).

3. Mayo, M. A. et al. in Virus Taxonomy. Eighth Report of the International Committee on Taxonomy of Viruses (eds Fauquet, C. M., Mayo, M. A., Maniloff, J., Desselberger, U. \& Ball, L. A.) 1161-1169 (Elsevier-Academic, London, 2005).

4. Hickman, A. B. et al. Structural unity among viral origin binding proteins: crystal structure of the nuclease domain of adeno-associated virus Rep. Mol. Cell 10, 327-337 (2002).

5. Berns, K. I. Parvovirus replication. Microbiol. Rev. $\mathbf{5 4}$ 316-329 (1990)

6. Claverie, J. M. \& Abergel, C. Mimivirus and its virophage. Annu. Rev. Genet. 43, 49-66 (2009).

7. Forterre, P. Manipulation of cellular syntheses and the nature of viruses: the virocell concept. C. R. Chim. 14, 392-399 (2011).

8. Kassanis, B. Properties and behaviour of a virus depending for its multiplication on another. J. Gen. Microbiol. 27, 477-488 (1962).

Competing interests statement

The authors declare no competing financial interests. 